\title{
Using Facebook as an e-portfolio in enhancing pre-service teachers' professional development
}

\author{
Muhammad Kamarul Kabilan \\ Universiti Sains Malaysia
}

\begin{abstract}
This study aims to determine if Facebook, when used as an online teacher portfolio (OTP), could contribute meaningfully to pre-service teachers' professional development (PD) and in what ways the OTP can be meaningful. Pre-service teachers $(n=91)$ were asked to develop OTP using Facebook and engage in learning and professional development (PD) activities for 14 weeks. Questionnaires, open-ended items and reflective reports were used to collect data and it was found that many of the pre-service teachers benefitted quite significantly in terms of their development as future teachers through these five facets: (i) community of practice; (ii) professional learning and identity; (iii) relevant skills; (iv) resources; and (v) confidence.
\end{abstract}

\section{Introduction}

Pre-service teachers tend to be satisfied with their existing knowledge and practices, and seldom do they attempt to generate new knowledge, create and experiment with new practices or validate their own ideas (Alfonso, 2001; Kabilan, 2007). If this is not addressed, then these future teachers have the tendency to depend heavily on their preconceived ideas, thoughts and understandings of how they should teach, learn and develop as a teacher rather than consistently, constructively and critically reflect on their teaching practices.

Darling-Hammond (2006) suggests that in order to overcome deficiencies and other variables that influence teachers' work and their effectiveness, one solution is to engage pre-service teachers in performance assessment, which will help pre-service teachers gain deeper understanding of what they lack and what they need to further improve. According to Darling-Hammond (2006), performance assessment has the capability to evaluate "what novice teachers have learned and organize learning, deliberately marrying knowledge and application, rather than assuming one automatically follows from the other" (p. 114). Eventually, pre-service teachers will progress towards enactment of knowledge and learning in practice rather than remain at a level of mere intellectual understanding. Examples of performance assessment include, among others, portfolio (and electronic portfolio), project work and seminar presentations.

Creating and maintaining e-portfolio are advantageous to pre-service teachers because these practices provide them the "opportunity to consciously monitor and assess their own current knowledge and to understand pedagogical and subject contents continuously and consistently" (Kabilan \& Khan, 2012; p. 1018). Electronic portfolios are also effective in guiding pre-service teachers' independent learning, selfevaluation and reflective practices (Klenowski, 2000), creating a feeling of self-satisfaction as a future professional (Sherry \& Bartlett, 2005), engaging in deep, sustainable and transformational learning experiences (Tosh, Werdmuller, Chen, Light, \& Haywood, 2006), and enriching perspectives with diverse approaches, views and activities of learning (O’Brien, 2006).

In this study of Malaysian pre-service teachers, Facebook was chosen as the e-portfolio platform for two main reasons. First, Facebook is a popular social media and networking site with more than 1.23 billion active users (as of February 2014, http://zephoria.com) worldwide. In Malaysia, it is the most visited social media website with 10.4 million users, of which 3.5 million are learners aged between 18 and 24 (Subramaniam, 2014). Through Facebook, users can connect and interact with members of various communities with similar interests, and educators can support their learning and development individually and as a community of practice (Godwin-Jones, 2008). Second, despite Facebook's popularity and the recognition that PD programmes and experiences can be provided with the aid of technology (Kabilan, 2005; Kabilan \& Embi, 2006; Kabilan, Wan Adlina, \& Embi, 2011), a literature search reveals that there is a paucity of research on the use of Facebook as an e-portfolio in enhancing teachers' PD have been published. 
Hence, this research utilised Facebook as an e-portfolio to enhance the PD of Malaysian pre-service teachers of various subjects and across curriculum. Pre-service teachers were selected because they often lack confidence and pedagogical content knowledge (Aida Suraya, Ramlah, Habsah, Sharifah Kartini, \& Mat Rofa, 2006), awareness of meaningful classroom practices (Kabilan, 2007), and assessment and teaching and learning practices (Nykvist, 2009). Apart from enriching the literature, this research provides researchers, educators and PD facilitators with valuable knowledge and insights into the potential of Facebook to engage individuals as a community of practice in meaningful and relevant costfree PD.

The main aims of the study were to determine if Facebook can be utilised as an e-portfolio to enhance pre-service teachers' development experiences and to identify its benefits as an e-portfolio, particularly in terms of its contribution, if any, to the pre-service teachers' development. This research was guided by the following research questions:

i. Can Facebook be utilised as an e-portfolio to enhance and support teacher PD meaningfully?

ii. How does the Facebook environment, when utilised as an e-portfolio, contribute meaningfully to pre-service teachers' PD experiences - individually and as a community of practice?

\section{Literature review and theoretical perspectives}

A review of Facebook use by students and teachers by Khe (2011) reveals that Facebook has "very little educational use" (p. 668) since there is limited empirical evidence to support such use. Junco (2015) suggests that Facebook may hinder learning processes and negatively influence academic performance. Furthermore, several key issues that concern privacy, safety and inappropriate contents in Facebook have curtailed its use in educational contexts. Papandrea (2012) critically highlights actual cases whereby some educational institutions have restricted electronic communication between teachers and students to avoid inappropriate relationships from developing. Kwan and Skoric (2013) too find that intensity of Facebook use and engagement may lead to bullying and victimisation of students in the Facebook community.

Nevertheless, Facebook can be a valuable pedagogical tool and a communicative platform (Papandera, 2012), as well as a meaningful learning environment (Kabilan, Ahmad, \& Abidin, 2010). Roblyer, McDaniel, Webb, Herman, and Witty (2010) and Selwyn (2009) concur that researching Facebook is a worthwhile effort to understand future research and learning possibilities using online social media. It is considered by learners as a source of learning (Arouri, 2015) that can be harnessed for more effective distribution and sharing of learning materials and increased cooperative learning between students (Asterhan \& Rosenberg, 2015). These meaningful activities and engagement on Facebook have cultivated weak learners to become comfortable while discussing, giving opinions and forging relationships with peers when online (Promnitz-Hayashi, 2011) due to the pedagogical, social and technological tools of Facebook as a learning management system (Wang, Woo, Quek, Yang, \& Liu, 2012) that encourage, support and sustain meaningful interaction between learners. In sharing information using Facebook, students are actually "communicating with larger audiences with whom they might have no personal relationship, but are doing so because they perceive the value of sharing their knowledge with the larger public" (Beach, 2012; p. 48).

In this study, the notion of community of practice (CoP) is integral. In terms of PD, the link between CoP and, the teachers' practices and development is strong. This nexus raises pertinent issues such as the nature of socialisation in teaching practices, the type of CoP activities engaged in, the processes of CoPs that lead to productive PD and, the potentials of CoP in enhancing learning processes (Schwen \& Hara, 2004). CoP is an activity system or groups of people or participants who share understandings about what they do and what that means in their lives and community (Lave \& Wenger, 1991). Other relevant aspects of PD using e-portfolio include: (a) sharing of sets of problems, common issues and passions about a topic; (b) exploring ideas and creating tools, standards and documents; and (c) deepening of knowledge and expertise by interacting with others on an ongoing basis (Wenger, McDermott \& Snyder, 2002).

An important concept in CoP is the notion of domain - the problems and/or issues that members experience. Wenger, McDermott, and Snyder (2002) signify the importance of domain in organising the knowledge created by the CoP that assists the members to organise, share and distinguish ideas that are significant/insignificant ones. Members of a $\mathrm{CoP}$ are expected to commit to the domains and share 
practices that they have created in resolving the domains. Without this commitment, the CoP is rather meaningless. It is just a group with no aims and directions. According to Hardey, Tinney, and Davies (2012), such organisation of knowledge is an important facet of e-portfolio use that can lead to knowledge construction and refinement.

In e-portfolios, when teachers share and compare their knowledge organisation (in the form of artefacts) and construction, observations and understanding with others, learning is "transformed from a personal (learning) activity to a social (learning) activity" as the teachers are exposed to challenges and confrontations of their own "meanings through interaction with others" (Kanuka \& Anderson, 1998; p. 74). This would facilitate PD in ways that include among others, confidence and self-growth (Kilbane \& Milman, 2003); information and communication technology (ICT) skills (Abrami \& Barrett, 2005); creativity (Campbell, Cignetti, Melenyzer, Nettles, \& Wyman, 2004); meaningful learning (O’Brien, 2006); independent and collaborative learning (SongHao, Kenji, Takara, \& Takashi, 2008); and pedagogical knowledge and skills (Kabilan \& Khan, 2012). In terms of PD, using Facebook as an eportfolio is a systematic and deliberate decision to design a learning environment that promotes a meaningful learning culture, and utilize it as a platform that scaffolds relationships between learners (Lock, 2006), Many researchers regard Facebook as a meaningful socialisation tool that could be used for learning (see Ellison, Steinfield, \& Lampe, 2007; Madge, Meek, Wellens, \& Hooley, 2009). Therefore the focus of this study is to discern if Facebook can be an appropriate online environment to integrate one's individualistic learning activity into a meaningful and socially collaborative learning activity through eportfolio, and thus contribute significantly to the teachers' PD.

The above individualistic learning resonates with Mezirow's (1990, 2000) theory of transformative learning as "stages in cognitive restructuring and integration of experience, action, and reflection" (Stansberry \& Kymes, 2007; p. 489), whereby individuals focus and learn as reflective learners. In addition, Willink and Jacobs (2012) assent that OTP can "foster transformation in teacher beliefs through critical reflection, ownership of learning, and personal agency" (p. 18). These are the features that are integrated into the OTP in this study, whereby elements of transformative learning, critical reflection and performance assessment, are interwoven - each overlapping each other and simultaneously, each affecting each other.

\section{Methods}

This study, conducted in a Malaysian university, utilised a mixed method research design, which involved the gathering of qualitative and quantitative data that provide a better understanding of how Facebook, when utilised as an e-portfolio, enhanced and supported meaningful pre-service teacher' development experiences. This design enabled the drawing of a complete picture by identifying trend and generalisations, which include in-depth and comprehensive knowledge of participants' perspectives (Creswell \& Clark, 2007).

\section{The participants and context of research}

The participants involved in this research were 91 pre-service teachers (12 males and 79 females) from Universiti Sains Malaysia. All 91 were in their final semester of their Bachelor of Education academic programme. They specialised in various fields, including teaching English, mother tongue/native language, history, science and geography. They were enrolled in the Information and Communication Technology in Education course, which aimed to equip students with the knowledge and skills to use various current interactive ICT tools and the pedagogies of using them appropriately and effectively across the curriculum (Universiti Sains Malaysia, 2010). The course's assessment was $100 \%$ coursework that focused on two online project works; one of it is the online teacher portfolio (OTP) that is worth 35 marks. As part of their course requirement, students were asked to individually create, develop and maintain an OTP using Facebook for 14 weeks and an individual report to explain their OTP.

\section{OTP implementation}

The purposes of creating, developing and maintaining an OTP were to: (a) describe, display, share and discuss/dissect their teaching philosophies; and (b) describe, display, share and discuss/dissect artefacts related to one's own PD activities and experiences (past or current ones). The specific roles and activities 
that were performed by the researcher and the participants (chronological order) during the 14 weeks are listed in Table 1. Some of these activities were continuous and overlapped with others. Nevertheless, these activities can be categorised into 3 main phases:

Table 1

3 Phases of Research Activities

\begin{tabular}{|c|c|}
\hline \multicolumn{2}{|c|}{ PHASE 1: Introduce and Prepare (Week 1 - 3) } \\
\hline Researcher's roles & Participants' roles \\
\hline $\begin{array}{ll}\text { i. } & \text { Explained requirement for assessment of } \\
\text { course }-2 \text { project works. } \\
\text { ii. } \\
\text { Gave instructions on using Facebook for the } \\
\text { course. } \\
\text { iii. Lecture on Online Professional Development } \\
\text { by guest lecturer (Week 2). } \\
\text { iv. Reviewed artefacts uploaded by participants } \\
\text { during Week } 1 \text { - Week 3. }\end{array}$ & $\begin{array}{l}\text { i. Introduced themselves on the researcher's } \\
\text { Facebook. This was their first artefact and } \\
\text { completed by Week 1. } \\
\text { ii. Uploaded their teaching philosophies, beliefs } \\
\text { and ideas (using Facebook Notes) } \\
\text { iii. Clarified and explained their teaching } \\
\text { philosophies, completed by Week } 2 \text {. }\end{array}$ \\
\hline \multicolumn{2}{|c|}{ PHASE 2: Participate, Engage \& Maintain (Week 1 - 13) } \\
\hline Researcher's roles & Participants' roles \\
\hline $\begin{array}{l}\text { i. Gave input, particularly on the contents } \\
\text { related to PD shared by participants on } \\
\text { Facebook. This was done in three ways - } \\
\text { through Facebook Comments and Message } \\
\text { and through clarification during class } \\
\text { lectures. } \\
\text { ii. The researcher monitored and guided the } \\
\text { discussions that were emerging among } \\
\text { participants, ensuring that the discussions } \\
\text { were purposeful and related to PD issues. } \\
\text { iii. In Week 7, an open-ended item questionnaire } \\
\text { was posted in the researcher's Facebook } \\
\text { page to gauge participants' perceptions of } \\
\text { OTP and their overall progress in OTP. }\end{array}$ & $\begin{array}{l}\text { i. } \\
\text { oneginning Week 2, posted/uploaded at least } \\
\text { ii. Suggested and uploaded teaching ideas (using } \\
\text { Notes) and shared teaching materials such } \\
\text { images and pictures and videos. } \\
\text { iii. Made comments, initiated discussions, } \\
\text { uploaded materials (all related to educational } \\
\text { issues). } 11 \\
\text { iv. Completed the open-ended questionnaire and } \\
\text { submitted as an initial report of their OTP to } \\
\text { the researcher via email. }\end{array}$ \\
\hline \multicolumn{2}{|c|}{ PHASE 3: Reflect \& Report (Week 13-14) } \\
\hline Researcher's roles & Participants' roles \\
\hline $\begin{array}{l}\text { i. Posted the format and structure of the report } \\
\text { including a 2-week deadline for completion } \\
\text { of their reports. } \\
\text { ii. Evaluated the reports, and this evaluation } \\
\text { contributed to the overall assessment of the } \\
\text { participants' OTP. }\end{array}$ & $\begin{array}{l}\text { i. Prepared a report (5-8 pages) that included: } \\
\text { - explanations on the concept of his/her OTP } \\
\text { (including teaching philosophies); and } \\
\text { - a 2-page reflection on how the use of } \\
\text { Facebook as OTP was useful or not useful to } \\
\text { their PD. }\end{array}$ \\
\hline
\end{tabular}

The researcher, who was also the course coordinator (CC), refrained from intervening deeply with the students' learning. For the first 3 weeks, the CC was quite involved with providing the relevant information, explaining the necessary procedures and, organising and managing the students' learning (see Table 1). After 3 weeks, the learners worked independently and in collaboration with their peers, with almost no intervention from the $\mathrm{CC}$. This also ensured that the learners were free to express their views and ideas in the OTP. In terms of assessment, only the students' reports and OTP were evaluated and graded. The open-ended questionnaire and reflection report were not graded and were used as the sources of data for this research. The above information was relayed to the students during the first lecture, and they agreed to participate willingly in this research and give their cooperation.

\section{Data Collection Methods}


Three types of data were used in order to answer the research questions of this study: quantitative data (descriptive), open-ended responses and reflection reports. According to Thurmond (2001), such approach enables the triangulation of data, which then increases the validity of the study, in this case depicting the actual contexts and scenarios of the pre-service teachers' PD experiences in an OTP using Facebook.

Open-ended questionnaire (OEQ)

There are 4 main sections in the OEQ: (1) Demographic data of participants; (2) Facebook (membership and access); (3) Facebook as OTP for PD; and (4) Overall view/perceptions of OTP. Quantitative data were obtained to answer the first research question, "Can Facebook be utilised as an e-portfolio to enhance and support teacher PD meaningfully?" Qualitative data were collected to answer the second research question, "How does the Facebook environment (utilised as an e-portfolio) contribute meaningful for the pre-service teachers' PD experiences?"

The items in the OEQ explored: (1) the participants' emotions and satisfaction with their PD; (2) different activities in the Facebook environment that were meaningful; (3) the various benefits of PD as experienced in Facebook; and (4) the usefulness of Facebook for the participants' future practices as a professional. These four areas of research facilitated thorough and meaningful investigation of PD that looked at the pre-service teachers" "values, beliefs and assumptions about teaching and their ways of seeing the world" as suggested by Cranton and King (2003, p. 33). Johnson and Turner's (2003) idea of using multiple items in collecting qualitative data was adopted because it provided a thorough and detailed description and understanding of the participants' experiences, which was an abstract construct that needed to be defined and measured comprehensively.

\section{Reflection report $(R R)$}

The participants were asked to reflect on their overall experiences with Facebook as OTP, focusing on how the use of Facebook as OTP was useful or not useful to their PD. The aim is to gauge the pre-service teachers' ability to: (1) evaluate their practices; (2) understand their thoughts of teaching and learning; and (3) comprehend the complexity of their intellectual and emotional challenges (Hammerness, DarlingHammond, \& Shulman, 2002).

\section{Data Analysis}

Quantitative data obtained from OEQ were analysed using the descriptive statistics frequency $(f)$ and percentage (\%) to indicate the participants' views of Facebook as a useful OTP for meaningful PD. For the purposes of identification and data analysis, qualitative data were identified using a systematic code. For example, OEQ1 referred to "qualitative data obtained from the 1st participant's open-ended questionnaire" and RR1 referred to "qualitative data obtained from the 1st participant's reflective report".

These qualitative data were analysed using the thematic analysis, that is, the patterns and themes within the data were identified, analysed and reported by minimal organisation but with rich description of data that were then used to interpret various aspects of the pre-service teachers' PD. The themes for this research were identified via a 5-stage process as suggested by Braun and Clarke (2006):

i) Becoming familiar with the data: Reading all data for overall comprehension.

ii) Generating initial codes: Initial codes were identified by keywords or/and phrases or/and sentences that directly indicated ideas, views, concepts and notions of professional development.

iii) Searching for themes: Similar codes that formed a single theme were put together. Based on all the initial codes, an initial theme was developed by looking at the similarities of each code.

iv) Reviewing themes: The themes were reviewed. Irrelevant themes were either moved or collapsed or segregated, or renamed.

v) Defining and naming theme:- The themes (or categories) were named, defined and discussed in the findings' section by using excerpts, phrases, sentences and paragraphs.

\section{Findings and discussions}

Prior to this OTP project, 85 participants (97.7\%) were already Facebook users who logged onto Facebook 1.2 times per week (on average). During the OTP project, the participants logged onto the 
Facebook 1.3 times per week (on average). This indicates there was little difference in the number of times participants logged onto to Facebook before and during the OTP project.

\section{Use of Facebook as OTP to enhance and support meaningful PD}

Most of the pre-service teachers in this study believed Facebook can be used as an OTP to enhance and support meaningful PD $(f=77 ; 88.5 \%)$. In terms of enjoyment of the OTP project, 59 pre-service teachers $(67.8 \%)$ enjoyed it, $14(16.1 \%)$ enjoyed it moderately while another $14(16.1 \%)$ did not enjoy participating in the OTP project. When asked if the participants would continue OTP when they become teachers, the majority believed they will $(f=75 ; 86.2 \%)$. From the above data, the pre-service teachers strongly believed that Facebook can be used as an OTP to enhance and support their PD meaningfully in future for their PD endeavours as practising teachers. However, the more critical issue here is how does the Facebook environment, when utilised as an e-portfolio, contribute meaningfully to the pre-service teachers' PD experiences.

\section{How does Facebook (as OTP) contribute meaningfully to PD?}

The qualitative data collected in the form of OEQ, RR and artefacts indicate that Facebook (as OTP) enhanced and supported meaningful PD of the pre-service teachers through five facets: (i) community of practice; (ii) professional learning and identity; (iii) relevant skills; (iv) resources; and (v) confidence.

\section{Community of practice}

Participants in this study acknowledged that the OTP engaged them in a community of practice that enabled them to: (i) express one's "point of views towards teaching and learning process" (OEQ17); (ii) share and exchange materials/information (OEQ79, RR74), thoughts (OEQ66, RR27), ideas (RR27, RR63), knowledge (OEQ3, RR63) and views (OEQ44, RR27); and (iii) learn from each other (OEQ79, RR82). They were able to do the above activities as a community of practice because they "feel accepted and somehow there is a sense of belonging to a community while interacting with other future teachers" (RR2). Others also felt this sense of belonging when they share their thoughts in the OTP (OEQ27) and members of OTP "help and encourage each other for our own improvement" (OEQ90). This sense of belonging was achieved through interaction among the members of OTP:

[S]haring my opinions with other people, made our interaction livelier and consists of twoway communication where we post our comments and the comments are replied by other people instead of me just posting my materials for everyone to see and no feedback is received. (RR82)

Using various tools in Facebook, the participants collaborated and networked as part of their practices in the OTP. This is because, as explained earlier by Tseng and Kuo (2014), as a member of a CoP, learners engage in various meaningful activities that would contribute to closer connections among the $\mathrm{CoP}$ members, and eventually lead to a greater sense of belonging to a community of practice and working together towards a common goal. Kabilan, Wan Adlina and Embi (2011) defined the above as the "practice of reconfiguring and refining new knowledge" (p. 110) that is accomplished by individuals working together in a community of practice. Wenger (1998) emphasised that an individual's personal experiences and his/her learning and acquisition of certain competency interact closely, and the tension that surrounds it is maintained throughout his/her experience in a $\mathrm{CoP}$. In the same manner, R5 had carefully organised and selected her OTP collection that "is made up of my own knowledge as well as the knowledge from my peers". She reconstructed new knowledge using her existing knowledge as well as newly gained knowledge from peers that enabled her to evolve, grow and advance as a teacher.

\section{Professional learning and identity}

At the beginning, many participants had negative perceptions and views of the OTP project, were confused of its aims and procedures, frustrated, and were sceptical of its potential for their learning or contributions to their development (RR48 \& OEQ79). However, after some time of getting used to the procedures in the OTP, the participants begin to learn to be selective, to ignore the rubbish and read the good comments/articles/debates (RR67) and to plan their OTP carefully (RR16). They gradually began to construct and develop OTP (RR79) that was based on their own teaching principles and beliefs (RR48), in accordance with their teaching philosophies (RR5) and parallel with their goals and objectives (RR60). 
Their construction and development of OTP included collecting, selecting, writing, commenting, uploading and updating relevant information/materials/artifacts onto their respective Facebook (OEQ8, OEQ66).

Gradually, participants' attitudes towards OTP changed from negative repulsion to positive acceptance (RR67). They became more responsible for their own sake (OEQ72) and willing to spend more time engaging in Facebook (OEQ79) since they were personally involved in their OTP (RR48) and getting excited about the project (OEQ23). Many realised that the OTP project was beneficial in terms of their professional learning (OEQ25 \& RR3) and future career (OEQ83 \& RR25). Many also indicated gaining of new knowledge related to teaching and learning (OEQ9 \& RR74).

The participant had begun rethinking their own learning as a professional and as a future teacher (OEQ27). OEQ63 noted how OTP helped her "to look back and reflect my previous and current activities in order to obtain new knowledge and improve my soft skills" and set her goals and objectives as a teacher in the OTP, to guide her towards a systematic teaching and learning pace. RR14 explained:

[OTP] made it more convenient to organise my activities effectively. I learnt to plan my lessons well and also to reflect on my preparation of my lessons. Many a times, I only plan my activities without reflecting whether my activities could be carried out successfully or not. This Facebook that I used for our OTP helped me to be aware of that.

Participants also realised that after their experiences in their OTP, they had to seriously (re)consider their professional identity in terms of what kind of teacher they wanted to be. This is because, as OEQ90 admitted, "[Previously before OTP], as a future teacher, I only think of the objectives of my lesson plans but the notion of the goal of being a future teacher or my own development has never came to my mind.]. The OTP project had motivated her to rethink her aim of being a teacher "not only just to teach students but also to improve my own self". Similarly, RR33 confessed, "What exactly is my goal or objective in my development as a future teacher? It pained me to admit it but I had never given it any thought before." RR33 realised the importance of having such a goal before stepping into the world of teaching.

Generally, the participants wanted to be effective in-service teachers. RR82 stated the OTP had "awakened my spirit and determination to be a better teacher in future", whereas OEQ87 wanted to become a knowledgeable teacher by educating herself to become more aware of the issues that arise in the teaching profession. Many pre-service teachers in this study recognised and acknowledged the concept of effective teachers and teaching as an integral element in their future professional endeavour. This is the key element in determining their professional identity:

My mind that was once narrow and old fashioned now has transformed (and still learning) into a brand new one that embraces new technology and manipulating ICT to work for me and the greater good of my future class/students. I never realised I could make ICT work for me and use it as a teaching aid in making my teaching more effective. (RR67)

Based on the research data, the pre-service teachers identified themselves in the OTP by learning, experiencing, doing, sharing, and developing a sense of belonging to each other through an elaborate yet meaningful socialisation process - a concept strongly advocated by Wenger (1998). Though many participants were reluctant in the beginning and had to accept OTP as a new learning and collaborative environment, at later stages they began to cognitively restructure their learning and integrate their experiences, actions and reflections in the OTP, leading to a formation of professional learning and identity through transformative learning, a process that is also reported by Stansberry and Kymes (2007). Shanyang, Grasmuck, and Martin (2008) earlier suggested that formation of identity in an online CoP is a social outcome and not is not based on individual characteristics. This implies that teachers' identities in this study could have been developed and characterised through a meaningful conscious socialisation process in the OTP. Through this mode of social learning, the reconstruction, reconfiguration and reuse of knowledge produced by pre-service teachers during OTP have motivated and dictated (to some extent) their future professional endeavour, and in the process, helped them discover themselves, particularly in terms of the kind of teachers that they want to be. Wenger (1998) argues that a CoP is responsible for the development of new competencies, for the continuity of concepts, artefacts and stories for the construction of new ideas, and for the application of what learned to new contexts and settings. Similarly, 
the OTP in this study, as a CoP, may well have contributed to the overall development of the pre-service teachers in this study.

\section{Relevant skills}

Three main skills were identified by the pre-service teachers: teaching skills, organisation skills and thinking skills. Most participants emphasised that engaging in OTP helped them to be organised and to develop their teaching skills. According to RR2, looking at others' OTP and their creative way of organising content of their OTP, inspired her to be "more systematic and organised in my teaching plan and ideas instead of bombarding that wall with everything randomly". The OTP project required participants to research in order to get a better understanding of issues (OEQ29), to reflect and think creatively and critically before and after engaging in any of the activities:

I had shared comments, picture, video and notes to be discussed with my friends. These activities require me to think more creative and become more. In updating my status, I have to think critically and out of the box. I also become aware of my grammar. When others respond to my status, I need to think and search for appropriate answers to answer it. (OEQ46)

Participants gave careful thought to language accuracy and to the selection and upload of meaningful content. They worried about making mistakes in terms of grammar and content because the OTP will be viewed and commented from the perspective of professional practice (OEQ37). Participants were careful in: (a) communicating and interacting with others; (b) displaying and presenting artefacts and materials; and (c) commenting and discussing on issues so that their ideas and views are linguistically appropriate, critical, beneficial and acceptable to others. These aims were attained through the continuous literacy practices in the OTP that facilitate the participants to reflect, (re)construct, (re)organise, (re)think and (re)evaluate sentences, artefacts, thoughts and ideas. Such learning are plausible, as Hammond (2000) pointed out, learners in their attempt to learn, would try to make sense of new ideas, explore into unknown situations and look at things from different and new angles.

\section{Resources}

According to RR8, the Wall in Facebook was a crucial element that functions as a resource centre and an environment where most of her meaningful interaction took place and helped her to develop and create her own ideas and become a resourceful future teacher. OEQ8 also believed that the contents and resources in Facebook would be really helpful for her teaching practicum. Other participants (for example, OEQ27, RR80 and OEQ82) also believe Facebook as the OTP has become a vital resource centre for: (a) obtaining current information and news related to education; (b) exchanging, sharing and collecting of materials, ideas, views and experiences related to education; and (c) engaging and initiating professional practices and spaces with others. OEQ82's views encapsulate these ideas:

I like the fact that we share our resources and materials with each other as this really saves time and make it easier for us to get useful information. The whole Facebook site has become an online database which is rich with information, ideas, and opinions. Other people's experiences have offered a variety of insight and opinion for me. I am exposed to a lot of interesting and mind opening facts which has helped me to grow wisely in terms of knowledge and experiences.

When the pre-service teachers' engage in various interactions, discussions, reflections, exchanging and sharing in their Facebook, the participants experienced meaningful knowledge construction that enhanced their PD experiences. This knowledge construction transpired when they carefully and critically selected, (re)configured and (re)created, and displayed artefacts that were significant to them individually and collectively as a CoP. The selection, reconfiguration, recreation and display of artefacts in OTP are also elements of performance assessments. In performance assessments, Cimer and Cakir (2010) postulate that learners actually use their knowledge and skills and don't merely do it for the sake of doing it. The entire network of the pre-service teachers' Facebook had become a sizable, intricate database and resource centre for any of the OTP members to be able to extract relevant materials or ideas and use them for teaching and learning purposes. To use the analogy by Kabilan and Embi (2006), and Schrum (1995), the OTP had developed into an oasis of knowledge - a vast and rich resource centre, which the pre-service teachers constructed, connected and developed, that could fulfil their PD needs. 


\section{Confidence}

Participants also gaining confidence as a result of participating in OTP, by: (a) expressing their ideas during discussion (OEQ13); (b) giving/receiving feedback/comments to/from others (OEQ13, OEQ14); (c) raising relevant issues that need to be discussed; (d) knowing and realising how to design and prepare lesson plans (OEQ30, OEQ31); (e) posting, sharing and exchanging of materials such as videos, photographs and pictures in the Facebook (RR40); and (f) reflecting on events, ideas and thoughts (RR30).

By doing this OTP, I came to realise that I had so much skills in myself that I did not know before. It helped me to proceed on to plan my lessons better. My self-knowledge about teaching also grew in time. I could see the confidence in my ability to work effectively in different settings. (RR14)

Similar to findings by Watkins (2013) and Orr et al. (2009), research results revealed an increase of the pre-service teachers' confidence level due to three key practices that are augmented in the OTP, for example, (a) building their knowledge based through knowledge construction; (b) empowering them with the process of decision making through the development of their OTP; and (c) engaging in collegial discussions, interactions and sharing. These practices, Maeroff (1988) postulated, would make pre-service teachers feel confident, feel better about themselves, make them think critically about how they should teach and would be more ready to make decisions that would positively affect their future schools.

\section{Dissenting views}

A small number of participants $(13.8 \%)$ believed they did not benefit from the OTP and were not likely to use Facebook as they felt that the OTP does not contribute much to their PD. RR15, for example, pointed out that the events in the Facebook were unorganised. In the beginning process of socialisation, there were "too many people discussing too many different topics, leading to confusion" (RR19). This finding contradicts findings from other research (e.g., Chou, 2011; Ernest \& Hopkins, 2013; Sari, 2012) that strongly indicate socialisation is an integral communal activity that significantly contributes to teachers' PD in terms of professional knowledge mastery and skills. RR16, RR22 and RR30 suggest that clear instructions and guidelines for the OTP should be given and should focus on a few topics per week and not "letting everyone post updates about anything or everything freely" (RR18). Perhaps, this strategy would help pre-service teachers to better understand and conceptualise the power of a community of practice in enhancing one's PD.

\section{Implications and conclusion}

Both quantitative and qualitative data confirm that Facebook is a potential tool for an OTP, one that can meaningfully enhance and support pre-service teachers' PD. This is possible due to the features of the Facebook environment and the tools available in this online social media that encourage an interactive socialisation process. This includes: collaboration; sharing of experiences, ideas and artefacts and building them into an online resource/database; learning from each other; networking and connecting to each other; and the continuous practices of supporting and encouraging of each other.

Through the above intricate and complex socialisation process in the OTP, most pre-service teachers in this study experienced transformative learning, critical reflection and performance assessment via personal learning and social learning in a CoP. through many of the activities, interactions and engagements that they encountered during the OTP process. Their experiences lead to enriched ideas and experiences that facilitated (re)construction, (re)configuration, and (re)fining of knowledge that was personal and meaningful to individual members of the OTP, as well as to the OTP community as a whole. They augmented their learning and development as a pre-service teacher, and realized the importance of engagement in future PD initiatives as an in-service teacher. Clearly, there is a nexus between transformative learning, critical reflection and performance assessment that are embedded in the OTP. This node leads to PD if both personal and social learning are heightened.

Although at the onset of the project participants were motivated by grades, they gradually began to identify the aforementioned socialisation processes as integral modes of self-learning and self- 
development. By selecting appropriate materials for the construction and development of their OTP, coupled with the various personal experiences and professional engagements in Facebook enabled participants to identify their professional portraits and discern the benefits and the overall value of OTP for their PD. The OTP process was able to bring and connect pre-service teachers from different backgrounds, regions, and cultures, in a virtual melting-pot for them to discover the views of different and diversified thoughts and perceptions of the world through a critical reflection and learning from the reflection of their own experiences. Previous research results suggest personal knowledge and experiences influence opinion and impact ones' professional views, leading to construction and reconstruction of knowledge (see Kagan, 1992; Lai \& Pek, 2012). Such influences add dimension to one's existing knowledge, contributes to the profundity of pre-service teachers' thoughts and ways of thinking and perceiving.

This study strengthens the notion forwarded by Darling-Hammond (2006) and Kabilan (2007), that empowering pre-service teachers is crucial in aiding them to make decisions and complete assignments in ways that generate ideas, views, knowledge and answers - ways that also engage them in the process of improving their effectiveness as future teachers. As the findings suggest and as supported by other research, using social networking such as Facebook as an OTP for pre-service teachers' learning and development must include an understanding of its purpose and a clear conceptualisation of the envisioned e-portfolio. Walker and Cheng (1996) identified understanding of purpose and conceptualisation of PD as the two of the most significant features of an effective and meaningful PD programme. Also, instructors should support learning and development processes in the OTP, as recommended by Watkins (2013). Kabilan and Khan (2012) believed that enlightening and engaging pre-service teachers in accepting OTP as a practice has future implications for their PD. Hence, future studies should also explore how instructors can support pre-service teachers' learning and development using a social network environment such as Facebook as an OTP. In addition, the entwined relationship between personal and professional facets of socialising in OTP warrants further examination, especially how personal connections may lead to PD.

In this study, the OTP has developed and connected the members of a CoP, facilitated knowledge construction, enhanced pre-service teachers' PD and created an organic online resource/database. Facebook has potential for "moving best practices and innovation quickly, accelerating knowledge creation and innovation" (Watkins, 2013; p. 23). This is especially in aspects of teacher PD that evolve continuously in terms of knowledge and practices. Nonetheless, in providing the above experiences for the pre-service teachers, some of the limitations and negative experiences voiced by the participants in this study should be addressed, particularly their initial views about creating portfolios and using Facebook or any other online social media for learning purposes. Therefore, the key pedagogical implications of this study are: (a) learners should be given clear instructions and guidelines on the implementation and processes of learning/socialisation in OTP; (b) instructors and educators should identify and address specific tasks and topics periodically that would keep the learners (individually and as a CoP) focused on achieving the desired PD and learning outcomes through OTP; and (c) pre-service teachers need to be made aware and realise that socialisation in Facebook as an OTP and CoP can be a quality learning process that can develop into an essential element that contributes to professionalisation, if structured and planned well.

On its own, Facebook is just another social network site but if used appropriately and purposefully, it offers an amalgamation of socialisation and professionalisation - two overlapping facets that influence and empower each other in meaningful and prevailing teacher education and development. Findings from this study indicate that an OTP embedded within a social network enhances and supports pre-service teachers' meaningful PD. Members become a community of practice, acquire professional learning and identity, and gain relevant pedagogical skills, resources and confidence. These are some of the tenets that most pre-service teachers in this study, as well as other contexts and settings, lack and need help with, and what teacher education programmes at many universities aim to achieve.

\section{References}

Abrami, P. C., \& Barrett, H. (2005). Directions for research and development on electronic portfolios. Canadian Journal of Learning and Technology, 31(3), 1-15. Retrieved from http://www.cjlt.ca/index.php/cjlt/article/view/92/86 
Afonso, C. (2001). Understanding student teachers' perceptions of the teaching and learning of English as a foreign language through their analysis of computer-generated materials. (Unpublished doctoral dissertation). King's College, University of London.

Aida Suraya, M. Y., Ramlah, H., Habsah, I., Sharifah Kartini, S. H., \& Mat Rofa, I. (2006). Confidence in teaching mathematics among Malaysian pre-service teachers. Journal of Science and Mathematics Education in SEA, 29(1), 1-20. Retrieved from www.recsam.edu.my/R\%26D_Journals/YEAR2006/jour06no.1/1-20.pdf

Arouri, Y. (2015). How Jordanian university students perceive the opportunities and challenges of using Facebook as a supplementary learning resource? International Journal of Emerging Technologies in Learning, 10(1), 46-54. doi:10.3991/ijet.v10i1.4265

Asterhan, C., \& Rosenberg, H. (2015). The promise, reality and dilemmas of secondary school teacherstudent interactions in Facebook: The teacher perspective. Computers \& Education, 85(5), 134-148. doi:10.1016/j.compedu.2015.02.003

Beach, R. (2012). Uses of digital tools and literacies in the English language arts classroom. Research in the Schools, 19(1), 45-59. Retrieved from http://www.msera.org/oldsite/Rits_191/Rits_191_Beach_5.pdf

Braun, V., \& Clarke, V. (2006) Using thematic analysis in psychology. Qualitative Research in Psychology, 3(2), 77-101. doi:10.1191/1478088706qp063oa

Campbell, D., Cignetti, P., Melenyzer, B., Nettles, D., \& Wyman, R. (2004). How to develop a professional portfolio: A manual for teachers. Boston, MA: Allyn \& Bacon.

Chou, C. M. (2011). Student teachers socialization development by teaching blog: Reflections and socialization strategies. Turkish Online Journal of Educational Technology, 10(2), 190-201. Retrieved from http://www.tojet.net/articles/v10i2/10219.pdf

Cimer, S. O., \& Cakır, I. (2010). Teachers' knowledge and practices of performance assessment. Procedia-Social and Behavioral Sciences, 2(2), 2661-2666.

Cranton, P., \& King, K. (2003). Transformative learning as a professional development goal. New Directions for Adult and Continuing Education, 98(2), 31-37. doi:10.1002/ace.97

Creswell, J., \& Clark, V. (2007). Designing and conducting mixed methods research. Thousand Oaks, CA: Sage.

Darling - Hammond, L. (2006). Powerful teacher education. San Francisco, CA: Jossey-Bass.

Ellison, N., Steinfield, C., \& Lampe, C. (2007). The benefits of Facebook 'friends:' Social capital and college students' use of online social network sites. Journal of Computer-Mediated Communication, 12(4), 1143-1168. doi:10.1111/j.1083-6101.2007.00367.x

Ernest, P., \& Hopkins, J. (2013). Coordination and teacher development in an online learning environment. CALICO Journal, 23(3), 551-568. Retrieved from https://calico.org/html/article_106.pdf

Godwin-Jones, R. (2008). Mobile computing technologies: Lighter, faster, smarter. Language Learning \& Technology, 12(3), 3-9. Retrieved from http://llt.msu.edu/vol12num3/emerging.pdf

Hammerness, K., Darling-Hammond, L., \& Shulman, L. (2002). Toward expert thinking: How curriculum case writing prompts the development of theory-based professional knowledge in student teachers. Teaching Education, 13(2), 219-243. doi:10.1080/1047621022000007594

Hammond, M. (2000). Communication within on-line forums: The opportunities, the constraints and the value of a communicative approach. Computers \& Education, 35(4): 251-262. doi:org/10.1016/S0360-1315(00)00037-3

Hardy, A., Tinney, J., \& Davies, S. (2012). Using e-portfolios to support trainee design and technology teachers in developing their subject knowledge. In T. Ginner, J. Hallströ, \& M. Hultén (Eds.), The PATT 26 Conference Stockholm, Sweden 26-30 June 2012: Technology Education in the 21 st Century (pp. 201-210). Stockholm: Linköping University Electronic Press

Johnson, B., \& Turner, L. A. (2003). Data collection strategies in mixed methods research. In A. Tashakkori, \& C. Teddlie (Eds.), Handbook of mixed methods in social and behavioral research (pp. 297-319). Thousand Oaks, CA: Sage.

Junco, R. (2015). Student class standing, Facebook use, and academic performance. Journal of Applied Developmental Psychology, 36(1), 18-29. doi:10.1016/j.appdev.2014.11.001

Kabilan, M. K. (2005). Online professional development: A literature analysis of teacher competency. Journal of Computing in Teacher Education, 21(2), 51-57. Retrieved from http://files.eric.ed.gov/fulltext/EJ876878.pdf

Kabilan, M. K. (2007). English language teachers reflecting on reflections: A Malaysian experience. TESOL Quarterly, 41(4), 681-705. doi:10.1002/j.1545-7249.2007.tb00099.x 
Kabilan, M. K., Ahmad, N., \& Abidin, M. J. Z. (2010). Facebook: An online environment for learning of English in higher education? The Internet and Higher Education, 13(4), 179-187. doi:10.1016/j.iheduc.2010.07.003

Kabilan, M. K., \& Embi, M. A. (2006). English language teachers' professional uses of e-mail. Teacher Development, 10(1), 87-103. doi:10.1080/13664530600587238

Kabilan, M. K., \& Khan, M. (2012). Assessing pre-service English language teachers' learning using eportfolios: Benefits, challenges and competencies gained. Computers and Education, 58(4), 10071020. doi:10.1016/j.compedu.2011.11.011

Kabilan, M. K., Wan Adlina, W. A., \&, Embi, M.A. (2011). Online collaboration of English language teachers for meaningful professional development experiences. English Teaching: Practice \& Critique, 10(4), 94-115. Retrieved from http://education.waikato.ac.nz/research/files/etpc/files/2011v10n4art6.pdf

Kagan, D. M. (1992). Professional growth among preservice and beginning teachers. Review of Educational Research, 62(2), 129-169. doi:org/10.3102/00346543062002129

Kanuka, H., \& Anderson, T. (1998). Online social interchange, discord, and knowledge construction. The Journal of Distance Education, 13(1), 57-74. Retrieved from http://cade.athabascau.ca/vol13.1/kanuka.html

Khe, F. H. (2011). Students' and teachers' use of Facebook. Computers in Human Behaviour, 27(2), 662676. Retrieved from http://www.sciencedirect.com/science/article/pii/S0747563210003651

Kilbane, C., \& Milman, N. (2003). The digital teaching portfolio handbook: A how-to-guide for educators. Boston, MA: Ally and Bacon.

Klenowski, V. (2000). Portfolios: Promoting teaching. Assessment in Education, 7(2), 215-236. doi:10.1080/713613329

Kwan, G., \& Skoric, M. (2013). Facebook bullying: An extension of battles in school. Computers in Human Behavior, 29(1), 16-25. doi:10.1016/j.chb.2012.07.014

Lai, P. K., \& Pek, H. L. (2012). Concept of professional socialization in nursing. International E-Journal of Science, Medicine \& Education, 6(1), 31-35. Retrieved from http://web.imu.edu.my/imuejournal/approved/7.Research_Lai_p31-35.pdf

Lave, J., \& Wenger, E. (1991). Situated learning: Legitimate peripheral participation. New York, NY: Cambridge University Press.

Lock, J.V. (2006). A new image: Online communities to facilitate teacher professional development. Journal of Technology and Teacher Education, 14(4), 663-678. Retrieved from http://www.aace.org/pubs/jtate/

Madge, C., Meek, J., Wellens, J., \& Hooley, T. (2009). Facebook, social integration and informal learning at university: 'It is more for socializing and talking to friends about work than for actually doing work'. Learning, Media \& Technology, 34(2), 141-155. doi:10.1080/17439880902923606

Maeroff, G. (1988). The empowerment of teachers: Overcoming the crisis of confidence. New York, NY: Teachers College Press.

Mezirow, J. (1990). Fostering critical reflection in adulthood: A guide to transformative and emancipatory learning. San Francisco, CA: Jossey-Bass.

Mezirow, J. (2000). Learning as transformation: Critical perspectives on a theory in progress. San Francisco, CA: Jossey-Bass.

Nykvist, S. (2009). A Malaysian tale: Pre-service teacher education and ICT integration for a better world. Proceedings of the 9th IFIP World Conference for Computers in Education (WCCE 2009), (pp. 1-9), Bento, Goncalves, Brazil.

O’Brien, K. (2006). E-portfolios as learning construction zones: Provost's perspective. In A. Jafari, \& C. Kaufman (Eds.), Handbook of research on e-portfolios (pp. 74-82). USA/UK: Idea Group Inc.

Orr, E., Sisic, M., Ross, C., Simmering, M., Arseneault, J., \& Orr, R. (2009). The influence of shyness on the use of Facebook in an undergraduate sample. CyberPsychology \& Behavior, 12(3), 337-340. doi:10.1089/cpb.2008.0214

Papandrea, M. (2012). Social media, public school teachers, and the First Amendment. North Carolina Law Review, 90, 1597-1642. Retrieved from http://ssrn.com/abstract=2063817

Promnitz-Hayashi, L. (2011). A learning success story using Facebook. Studies in Self-Access Learning Journal, 2(4), 309-316. Retrieved from http://sisaljournal.org/archives/dec11/promnitz-hayashi

Roblyer, M. D., McDaniel, M., Webb, M., Herman, J., \& Witty, J. V. (2010). Findings on Facebook in higher education: A comparison of college faculty and student uses and perceptions of social networking sites. Internet and Higher Education, 13(3), 134-140. doi:10.1016/j.iheduc.2010.03.002 
Sari, E. R. (2012). Online learning community: A case study of teacher professional development in Indonesia. Intercultural Education, 23(1), 63-72. doi:10.1080/14675986.2012.664755

Schrum, L. (1995). Educators and the Internet: A case study of professional development. Computers \& Education, 24(3), 221-228. doi:10.1016/0360-1315(95)00012-B

Schwen, T., \& Hara, N. (2004). Communities of practice: A metaphor for online design? In S. Barab, R. Kling, J. Gray (Eds.), Designing for virtual communities in the service of learning, (pp. 154-178). Cambridge: Cambridge University Press.

Selwyn, N. (2009). The digital native - myth and reality. Aslib Proceedings: New Information Perspectives, 61(4), 364-379. doi:10.1108/00012530910973776

Shanyang, Z., Grasmuck, S., \& Martin, J. (2008). Identity construction on Facebook: Digital empowerment in anchored relationships. Computers in Human Behaviour, 24(5), 1816-1836. doi:10.1016/j.chb.2008.02.012

Sherry, A. C., \& Bartlett, A. (2005). Worth of electronic portfolios to education majors: A 'two by four' perspective. Journal of Educational Technology Systems, 33(4), 399-419. doi:10.2190/FCCM-ET90FPDJ-040F

SongHao, H., Kenji, S., Takara, K., \& Takashi, M. (2008). Towards new collaborative e-learning and learning community using portfolio assessment. In G. Richards (Ed.), Proceedings of world conference on e-learning in corporate, government, healthcare, and higher education 2008 (pp. 1270-1275). Chesapeake, VA: AACE.

Stansberry, S., \& Kymes, A. (2007). Transformative learning through "teaching with technology" electronic portfolios. Journal of Adolescent \& Adult Literacy, 50(6), 488-496. Retrieved from http://www.jstor.org/stable/40015500

Thurmond, V. A. (2001). The point of triangulation. Journal of nursing scholarship, 33(3), 253-258.

Tosh, D., Werdmuller, B., Chen, H. L., Light, T. P., \& Haywood, J. (2006). The learning landscape: A conceptual framework for e-portfolios. In A. Jafari, \& C. Kaufman (Eds.), Handbook of research on e-portfolio (pp. 15-32). USA/UK: Idea Group Inc.

Tseng, F., \& Kuo, F. (2014). A study of social participation and knowledge sharing in the teachers' online professional community of practice. Computers \& Education, 72(2), 37-47. doi:10.1016/j.compedu.2013.10.005

Universiti Sains Malaysia, (2010). Instructional planning: PGT436E - Information and communication technology in education, School of Educational Studies, Universiti Sains Malaysia.

Walker, A., \& Cheng, Y. C. (1996). Professional development in Hong Kong primary schools: Beliefs, practices and change. Journal of Education for Teaching, 22(2), 197-212. doi:10.1080/02607479620359

Wang, C. M. (2012). Using Facebook for cross-cultural collaboration: The experience of students from Taiwan. Educational Media International, 49(1), 63-76. doi:10.1080/09523987.2012.662625

Wang, Q., Woo, H. L., Quek, C. L., Yang, Y., \& Liu, M. (2012). Using the Facebook group as a learning management system: An exploratory study. British Journal of Educational Technology, 43(3), 428438. doi:10.1111/j.1467-8535.2011.01195.x

Watkins, N. (2013). Social networking for addressing teacher isolation: A phenomenographic inquiry. (Unpublished doctoral dissertation). University of Oklahoma, US.

Wenger, E. (1998). Communities of practice. Cambridge: Cambridge University Press.

Wenger, E., McDermott, R., \& Snyder, W. M. (2002). Cultivating communities of practice. Boston, MA: Harvard Business School Press.

Willink, K., \& Jacobs, J. (2012). Teaching for change: Articulating, profiling, and assessing transformative learning through communicative capabilities. Journal of Transformative Education, 9(3), 143-164. doi:10.1177/1541344611436012.

Corresponding author: Muhammad Kamarul Kabilan, kabilan@usm.my

Australasian Journal of Educational Technology (c) 2016.

Please cite as: Kabilan, M. K. (2016). Using Facebook as an e-portfolio in enhancing pre-service teachers' professional development. Australasian Journal of Educational Technology, 32(1), 19-31. 